\title{
Coronavirus and pregnancy in Italy: results of the national population-based cohort study coordinated by the Italian Obstetric Surveillance System
}

alice maraschini ${ }^{1}$, Edoardo Corsi $^{2}$, Michele Salvatore ${ }^{1}$, Ilaria Lega ${ }^{3}$, Paola D'Aloja ${ }^{3}$, Serena Donati $^{1}$, Letizia Sampaolo ${ }^{1}$, Salvatore Alberico ${ }^{4}$, Paola Casucci ${ }^{5}$, Irene Cetin $^{6}$, Gabriella Dardanoni $^{7}$, Franco Doganiero ${ }^{8}$, Massimo Franchi ${ }^{9}$, Livio Leo $^{10}$, Marco Liberati $^{11}$, mariavittoria locci ${ }^{12}$, Claudio Martini ${ }^{13}$, Federico Mecacci ${ }^{14}$, Alessandra Meloni ${ }^{15}$, Anna Mignuoli $^{16}$, Luisa Mondo ${ }^{17}$, Enrica Perrone ${ }^{18}$, Luca Ramenghi ${ }^{19}$, Sergio Schettini ${ }^{20}$, Martin Steinkasserer $^{21}$, Saverio Tateo ${ }^{22}$, and Vito Trojano ${ }^{23}$

${ }^{1}$ Istituto Superiore di Sanita

${ }^{2}$ University of Rome Tor Vergata

${ }^{3}$ Istituto Superiore di Sanità

${ }^{4}$ Burlo Garofalo Pediatric Institute

${ }^{5}$ Regione Umbria

${ }^{6}$ Università degli Studi di Milano

${ }^{7}$ Regione Sicilia

${ }^{8}$ Ospedale Civile Antonio Cardarelli Campobasso

${ }^{9}$ University of Verona

${ }^{10}$ Ospedale Beauregard Valle D'AOSTA

${ }^{11}$ Università degli Studi Gabriele d'Annunzio Chieti Pescara

${ }^{12}$ Università degli Studi di Napoli Federico II

${ }^{13}$ Regione Marche

${ }^{14}$ University of Florence

${ }^{15}$ Regione Autonoma della Sardegna

${ }^{16}$ Regione Calabria

${ }^{17}$ ASL TO3

${ }^{18}$ Regione Emilia-Romagna

${ }^{19}$ Istituto Giannina Gaslini Istituto Pediatrico di Ricovero e Cura a Carattere Scientifico

${ }^{20}$ Azienda Ospedaliera S. Carlo Potenza

${ }^{21}$ Central Teaching Hospital of Bolzano/Bozen

${ }^{22}$ Ospedale Santa Chiara Trento

${ }^{23}$ Mater Day Hospital

May 18, 2020

\footnotetext{
Abstract

Objectives To describe a cohort of Italian women with confirmed COVID-19 infection admitted during pregnancy for out or inpatient hospital care, in order to provide rapid feedback for clinicians and policymakers. Design National population-based
} 
cohort study. Setting 297 Italian public and private maternity units. Population Pregnant women with COVID-19 infection confirmed by RT-PCR testing through nasopharyngeal swab and/or chest RX or CT findings and/or antibody response from maternal blood. Exclusion criteria: age $<18$ years, refusal to participate and inability to give consent to participation. Methods A network of 351 trained reference clinicians enrols eligible women after acquiring an informed consent and completes a data entry form through a secure web-based system. Main outcome measures COVID-19 pneumonia, invasive respiratory support, ICU admission, women's severe morbidity and mortality Results Over $80 \%$ of the 65 cases occurred in Northern Italy. Women's mean age is 33.8 years. Gestational age at presentation is [?]14 weeks in $15.6 \%$ of the cases, $15-27$ weeks in $51.6 \%$ and [?]28 weeks in $32.8 \%$ women. Pneumonia affects $41.5 \%$ of the cohort; three women have severe complications and are admitted to ICU. None has died. Conclusions The study describes the course of COVID-19 infection in a cohort of pregnant women, providing valuable information to improve clinical and logistical management of these cases. Questions arising from the study deserve further research.

\section{Tweetable abstract}

Italian population-based cohort study involving 65 pregnant women with COVID-19 infection

\section{Introduction}

The novel coronavirus SARS-CoV-2 is responsible for severe acute respiratory syndromes and has rapidly spread worldwide. The World Health Organization (WHO) recognised COVID-19 as a pandemic on March $11^{\text {th }}, 2020(1)$.

Prevention and control of COVID-19 infections are major concerns for pregnant women. The evidence currently available does not support SARS-CoV-2 virus vertical transmission $(2,3)$ and suggests that pregnant women are not at increased risk of severe adverse maternal and neonatal outcomes $(4,5)$. This situation is in contrast with previous studies showing that in pregnant women both H1N1 flu and previous Coronavirus infections, such as SARS and MERS, were associated with a higher risk of severe viral respiratory infections and with adverse maternal and neonatal outcomes when compared to the general population $(3,6,7)$.

To enhance scarce data from previous studies and boost research with a more in-depth assessment of the maternal and neonatal effects of SARS-CoV-2, the Italian Obstetric Surveillance System (ItOSS) (8) has launched a national population-based study. The project collects information on all SARS-CoV-2 confirmed cases in women receiving in or out patient hospital care during pregnancy or within 42 days from any pregnancy outcome.

In this time of uncertainty, the hope is that this project can provide timely information to support health operators dealing with clinical and organisational assistance of pregnancies complicated by COVID-19 in Italy and other countries facing the epidemic, today and in the forthcoming months.

The data collected and analysed distinguish different groups of women affected by COVID-19: women who reported to a hospital while pregnant; women hospitalised for miscarriage, voluntary termination, or to give birth; women hospitalised within 42 days of the outcome of the pregnancy. This distinction, with the wealth of details made available, facilitates a fuller and more in-depth picture of how to support women during pregnancy, childbirth, and postnatal care. This paper describes the women with confirmed COVID19 infection admitted to hospital during pregnancy for out or inpatient care, their symptoms and the course of the SARS-CoV-2 virus as well as its treatment.

\section{Methods}

The ItOSS launched a national population-based cohort study to collect information on all women with a confirmed COVID-19 infection receiving in or outpatient hospital care during pregnancy. A case is defined as a pregnant woman with COVID-19 infection confirmed by reverse transcriptase-polymerase chain reaction (RT-PCR) testing for the SARS-CoV-2 virus, through a nasopharyngeal swab, and/or chest X-ray (RX) or computed tomography (CT) findings, and/or through antibody response from maternal peripheral blood. 
The ItOSS relies on a network of trained reference clinicians, covering $91 \%$ of the nation's live births (10). The network was extended to a further seven Regions and two autonomous Provinces to reach nationwide coverage for the present study.

The study core outcomes include COVID-19 pneumonia, invasive respiratory support, ICU admission, women's severe morbidity and mortality.

A multidisciplinary expert group - including obstetricians and gynaecologists, maternal-foetal medicine specialists, neonatologists, paediatricians, anaesthesiologists, midwives, and infectious disease specialists revised the data entry form and pre-tested its online version.

The data entry form includes fields relating to women's socio-demographic characteristics, general and obstetric history, COVID-19 infection diagnosis, treatment and complications. A follow-up analysis will collect information on pregnancy outcomes, mode of delivery and maternal and neonatal outcomes.

The clinicians working in the network maternity units use a secure web-based data collection system to record incident cases. They received a manual for the use of the web-based system and have constant help-desk support.

On enrolment, women receive an informative note describing the study and informed consent to the participation is acquired. The ItOSS sends a weekly email to the contact clinicians of the health care facilities, reminding them to report the new cases. For each notified case, a link is sent for online data entry and a unique identifier code is generated. Assuming that data relating to the reported cases might be missing, a new request will be sent by email and, if further reminders are needed, the contact person will be reached by phone.

In case of maternal death from SARS-CoV-2 infection, the ItOSS maternal mortality surveillance system will allow verification and provide further information. The data are collected and processed by personnel in charge of ensuring confidentiality and security.

Since this is an observational study, the cohort size depends on the incidence of the disease.

The preliminary data analysis focused on descriptive statistics stratified by COVID-19 pneumonia occurrence. Significant differences between the two groups were assessed through the Fisher's exact test suitable for the analysis of small samples.

All the analyses were performed using the Statistical Package Stata/MP 14.2.

This study has not received any funding and was conducted without patient involvement due to lack of time and funds.

\section{Results}

From February 25 to April 22, 202015 Regions in Italy notified 65 pregnant women with confirmed COVID19 infection receiving in or outpatient hospital care. Of these, $55(84.6 \%)$ were notified by 5 Regions and 2 Autonomous Provinces located in the North of the country (Fig.1).

Italian Regions adopted different organisational models to face the epidemic and the vast majority centralised the admissions of suspected or positive COVID-19 women in dedicated hub hospitals. Overall, during the study period 11 pregnant women have been transferred to a hub from a different hospital.

This paper describes the first 65 cases admitted to hospital during pregnancy, $33.8 \%$ receiving outpatient care and $66.2 \%$ inpatient care either for antenatal complications of COVID-19 infection $(\mathrm{n}=38)$ or for medical $(\mathrm{n}=3)$ or obstetric $(\mathrm{n}=2)$ conditions.

The COVID-19 infection diagnosis was confirmed by RT-PCR testing in 63 cases, in 1 case through antibody response from maternal peripheral blood and in 1 case through chest RX. 
During the 14 days prior to symptom onset, just over half of the women reported having risk contacts. Specifically, 31 reported close contact with a confirmed or probable case and 4 reported entrance in a health care facility with confirmed SARS-CoV-2 cases.

Table 1 shows the women's socio-demographic and obstetric characteristics stratified by occurrence of COVID-19 pneumonia affecting $41.5 \%$ of the cohort. One case of Chlamydia pneumonia has been excluded from the stratified analysis presented in the tables. Gestational age at diagnosis ranges between 6 and 39 weeks, $15.6 \%$ of the women [?] 14 weeks, $51.6 \%$ between 15 and 27 weeks and $32.8 \%$ [?] 28 weeks of pregnancy. Women's mean age is 33.8 years $(\mathrm{SD}=5.5)$, and almost $70 \%$ of the women is multipara. Pregnant women without Italian citizenship develop COVID-19 pneumonia in a higher proportion compared to Italian women. Having at least one previous comorbidity is significantly associated to pneumonia diagnosis (p-value 0.002), obesity being the most frequently reported comorbidity (16.9\%) followed by autoimmune diseases $(6.2 \%)$.

Six per cent of the women had been administered the flu vaccine when pregnant, and 2 only quit smoking during pregnancy. No fetal growth restriction was diagnosed in any pregnancy.

At hospital admission, $10.8 \%$ of the women were asymptomatic. Table 2 describes the reported symptoms stratified by occurrence of pneumonia: cough (70.8\%), fever $(63.1 \%)$ and general weakness $(47.7 \%)$ being overall the most common. Dyspnea was reported by $66.7 \%$ of the women affected by pneumonia vs $18.9 \%$ of the unaffected (p-value 0.001). Overall, $41.5 \%$ of the enrolled women developed COVID-19 pneumonia.

Tab 3 describes the adopted diagnostic imaging techniques, the principal vital signs, laboratory reports and the therapeutic measures, stratified by occurrence of pneumonia among hospitalised women. Around half of the cases with confirmed pneumonia have been diagnosed through chest X-ray, 37\% received lung ultrasound alone or in association with chest X-ray, and $11 \%$ underwent chest TC. Among women without COVID-19 pneumonia, $46.7 \%$ has not undergone any diagnostic imaging techniques.

Body temperature over $37.5^{\circ} \mathrm{C}$ affected $40.7 \%$ of the women with pneumonia and $26.7 \%$ of those without, respectively $63.0 \%$ and $33.3 \%$ presented lymphopenia $\left(<1500 \mathrm{~mm}^{3}\right)$ and $44.4 \%$ and $6.7 \%$ had C-reactive protein $(\mathrm{CRP})$ values $>10 \mathrm{mg} / 100 \mathrm{ml}$.

The percentage of hospitalised women receiving at least one pharmacological treatment is $81.5 \%$ among women with pneumonia and $66.7 \%$ among the others. Overall, around half of the women were treated with antiviral drugs, hydroxichloroquine and empirical antibiotic therapy, with markedly higher percentages among women with confirmed COVID-19 pneumonia compared to the unaffected, as described in table 3.

Oxygen saturation $<95 \%$ was registered overall in $19 \%$ of the cases and in $26 \%$ of the women affected by COVID-19 pneumonia. Sixteen of the 30 blood gas analyses carried out were pathological, all but one in the group with confirmed pneumonia. Overall, $55.8 \%$ of the hospitalised women and $37 \%$ of those affected by COVID-19 pneumonia did not require any respiratory support. Among women with COVID-19 pneumonia, respectively $63 \%$ and $29.6 \%$ received non-invasive and invasive respiratory support; one underwent orotracheal intubation, none required extracorporeal membrane oxygenation (Tab.3).

Overall 3 women were in critical conditions due to severe morbidity ( 1 renal failure and 2 acute respiratory distress syndrome) (Tab. 2) and 3 were admitted to intensive care unit (ICU) for 5, 8 and 22 days respectively (Tab. 3). All unfavourable outcomes concerned women with pneumonia and no maternal deaths were recorded. Ninety per cent of the hospitalised women have been discharged, and the average hospital stay is 9.8 days (range $1-30$ days).

\section{Discussion}

\section{Main findings}

The paper describes the results on the first 65 cases of COVID-19 infection during pregnancy notified to the ItOSS, with the aim of providing rapid feedback for clinicians and policymakers. The cohort includes 10 women admitted for out or inpatient hospital care at [?]14 weeks of gestational age, 33 between 15 and 27 weeks and 21 [?]28 weeks. Women's mean age is 33.8 years $(\mathrm{SD}=5.5)$ and $68,3 \%$ are multiparas. Forty-one per 
cent of the women developed a COVID-19 pneumonia, previous comorbidity being significantly associated (p-value 0.002 ). At hospital admission $10.8 \%$ of the women were asymptomatic, and almost $50 \%$ reported not having had risk contacts during the 14 days prior to symptom onset. Overall, cough, fever and general weakness are the most common reported symptoms. Dyspnoea affects $66.7 \%$ of the women with pneumonia that in over $81.5 \%$ received at least one pharmacological treatment. Overall, $18.6 \%$ of the women received invasive respiratory support, 3 women developed severe maternal morbidity and 3 were admitted to intensive care unit, none died.

\section{Strengths and Limitations}

The cornerstones of the study are the national scale of the data collection alongside its population-based approach, the wealth of information garnered, and the opportunity to verify the data from the onset of the epidemic. Another asset is the gathering of data on cases of infection in the first trimester of pregnancy, which has not yet been described in the literature. Weak points include the analysis of preliminary data while disease transmission is still occurring, which limits the completeness of the study cohort and does not allow robust evaluation of all the variables under scrutiny. Data generalizability must take into account the prevalence of the condition in the different geographical areas and the characteristics of the population under study.

\section{Interpretation}

Total number of COVID-19 cases diagnosed by the Italian Regional Reference Laboratories among women of reproductive age was 28.661 in Italy until April 28 with about $51 \%$ observed in the age group 40-49 years (10). In our study, $84.6 \%$ of cases were registered in the northern regions, in line with the distribution on the total number of COVID-19 cases in Italy, of whom $80 \%$ were observed in the North during the study period (10).

Unlike studies regarding Chinese cases (11), which are retrospective and hospital-based, this research, like the UKOSS study (4), is prospective and population-based providing data to hypothesise several factors associated with the development of the disease during pregnancy.

Medical history of the enrolled women shows that multiparas and obese women are more frequent among those with COVID-19 infection compared to the background population of women in reproductive age $(12,13)$. The prevalence of obesity is $17 \%$ vs $7 \%$ among Italian women of reproductive age (14) and multiparas are $68 \%$ vs $49 \%$ of the women giving birth in the northern Italian regions $(15,16)$. Pregnant women with non-Italian citizenship have the same prevalence reported in Northern Italy among Italian residents in reproductive age $(14,15)$; however, the proportion presenting with pneumonia is higher compared to Italian women. This difference could be due to a delayed access to care among immigrant women. A higher than expected number of multiparas was affected, probably because living with several children - who are often asymptomatic may facilitate transmission.

The most common symptoms reported at the time of hospitalisation were fever (63\%), cough (71\%) and general weakness (48\%) like those described by the European Surveillance System (16) among the general population and those reported by pregnant women affected by COVID-19 in other countries $(4,5,11)$.

COVID-19 interstitial pneumonia affected $41.5 \%$ of hospitalised women. Previous comorbidities are significantly associated $(\mathrm{p}=0.002)$ to the risk of developing pneumonia. Comorbidities can drastically weaken the immune system and can cause conditions directly related to a greater risk of respiratory infections. Despite the small numbers of this preliminary analysis, the 4 women with autoimmune disease deserve attention.

The clinical picture of patients diagnosed with COVID-19 pneumonia is similar to those described in China and UK $(4,5,11)$, and it seems to be less serious than the effects on the general population (16) although this comparison should consider that the proportion of affected women who access care is greater among pregnant women than the general population. Similarly to the UKOSS study (4), among women affected by COVID-19 pneumonia, $11 \%$ had severe complications and were admitted to an ICU whereas among hospitalised patients with SARS-CoV-2, collected by the Italian Integrated surveillance, patients requiring 
ICU admissions were $22.8 \%$ (11). The lower number of women who developed severe symptoms compared to the general population is in line with the hypothesis that changes in the hormonal milieu in pregnancy, which influence immunological responses to viral pathogens, together with the physiological transition to a Type 2 $\mathrm{T}$ helper cells environment, which favours the expression of anti-inflammatory cytokines, help to reduce the inflammatory response that, in the very severe COVID-19 infections, is responsible for multi-organ damage $(17,18)$.

Compared to China (19), Italy uses X-rays more often than CT scans in diagnosis, while lung sonograms are used both for pneumonia diagnosis and monitoring. Validation of this diagnostic tool is of primary importance because it is simple, cheap, safe, and easy for OBGYN staff to access (20).

Lymphocyte counts and CRP are confirmed as the best laboratory parameters for testing for the presence of the disease both in women with pneumonia and in those without.

Effectiveness and safety of the drugs used are still uncertain due to the small number of cases and to the limited available knowledge (21). In the present cohort $76.7 \%$ of the hospitalised women received at least one pharmacological treatment and $33.8 \%$ has been treated with an antiviral (Tab.3). Treatments have been used in percentages considerably higher among women affected by pneumonia, mainly hydroxychloroquine and antivirals combined in approximately half of the cases alongside an empirical antibiotic treatment. Hydroxychloroquine is the most widely used drug, probably due to its ascertained safety profile in pregnant women (21). Information on the use of anticoagulants is lacking and a specific question has been recently added to the data collection form.

There are several open questions on clinical and public health policies aspects that emerge from the data analysis and that merit further research.

- Why do pregnant women affected by COVID-19 seem to be less at risk of serious respiratory infections and unfavourable maternal outcomes than in cases observed during the H1N1, MERS and SARS epidemics?

- What is the predictive value of various diagnostic methods using images in diagnosing and monitoring interstitial pneumonia?

- How effective and safe are the drugs in use and what are their clinical applications?

With a view to public health policy, it is essential to prepare for an effective vaccination campaign against seasonal flu so that next fall the uptake of flu jabs among pregnant women can be increased from current levels of $7 \%$. A further advantage of this would be to distinguish more easily between seasonal flu and COVID-19. The observation that almost half of the cohort had unaware at-risk contacts in the two weeks before the onset of symptoms highlights the issue of the asymptomatic infections impact and strengthens the recommendations of social distancing and contact tracing measures amongst pregnant women. Given the risk of asymptomatic viral shedding some hospitals started universal screening of patients on labour and delivery. Defining a single, nationwide strategy offering testing for pregnant women is of paramount importance in order to avoid distortions in the estimates of the frequency of the condition resulting from different regional approaches.

\section{Conclusion}

Owing to the difficulties health services are encountering in dealing with the enormous challenge posed by the COVID-19 pandemic, it is of strategic importance that vulnerable groups such as pregnant women and newborns are not left by the wayside and that quality research is promoted so that practical clinical recommendations can be devised and implemented (22). In this critical situation, ItOSS has been strategic, allowing data collection rapidly thanks to the availability of a population-based network, consolidated during the last 10 years to monitor maternal mortality and severe morbidity in the country $(23,24)$, and able to implement public health surveillance and research. The preliminary results described in the present study produced useful knowledge for clinical practice and generated research questions that will find an answer in further studies underway at international level. Our esteem and unconditional recognition go to caregivers 
involved both in frontline assistance and in the ItOSS research project, with whom we share the common goal of gaining a more in-depth evaluation of the effects of SARS-CoV-2 on mothers and newborns.

\section{Contribution to authorship}

SD conceived and conducted the study at national level, interpreted the results and wrote the article

AM performed the national data analysis, interpreted the results and revised the article

EC carried out the literature search and coordinated the data collection at national level

MAS performed the national data analysis, interpreted the results and revised the article

IL supported the study coordination and revised the article

PD supported the study coordination and revised the article

LS carried out the literature search

SA coordinated the study implementation in Friuli Venezia Giulia Region

PC coordinated the study implementation in Umbria Region

IC coordinated the study implementation in Lombardia Region

GD coordinated the study implementation in Sicily Region

FD coordinated the study implementation in Molise Region

MPF coordinated the study implementation in Veneto Region

LL coordinated the study implementation in Valle D'Aosta Region

ML coordinated the study implementation in Abruzzo Region

ML coordinated the study implementation in Campania Region

CM coordinated the study implementation in Marche Region

FM coordinated the study implementation in Tuscany Region

AM coordinated the study implementation in Sardinia Region

ADM coordinated the study implementation in Calabria Region

LM coordinated the study implementation in Piedmont Region

EP coordinated the study implementation in Emilia-Romagna Region

LR coordinated the study implementation in Liguria Region

SS coordinated the study implementation in Basilicata Region

MS coordinated the study implementation in Bozen Autonomous Province

ST coordinated the study implementation in Trento Autonomous Province

VT coordinated the study implementation in Puglia Region

The corresponding author attests that all listed authors meet authorship criteria and that no others meeting the criteria have been omitted.

\section{Details of ethics approval}

The Ethics Committee of the Italian National Institute of Health approved the project (Prot. $0010482 \mathrm{CE}$ 01.00, Rome 24/03/2020). 


\section{Funding}

This study has not received any funding.

\section{Acknowledgements}

We thank Silvia Andreozzi and Mauro Bucciarelli for their valuable technical support and assistance to the operation of the web-based data collection system.

We thank Clarissa Bostford for language editing.

Our heartfelt thanks go to all the clinicians working in the national network of maternity units (Appendix 1) for the assistance offered to women and for collecting the data, we thank all women who agreed to participate in the study.

Disclosure of interest

All authors have completed the ICMJE uniform disclosure form and declare no support from any organisation for the submitted work; no financial relationships with any organisations that might have an interest in the submitted work in the previous three years; no other relationships or activities that could appear to have influenced the submitted work.

\section{References}

1. WHO Virtual press conference on COVID-19-11 March 2020. [cited 2020 Apr 16]. Available from: https: //www. who. int/docs/default-source/coronaviruse/transcripts/who-audioemergencies-coronavirus-press-conference-full-and-final-11mar2020. pdf? sfursn= $c b 432 b b 3 \_2$

2. Wang C, Zhou YH, Yang HX et al. Intrauterine vertical transmission of SARS-CoV-2: what we know so far. Ultrasound Obstet Gynecol. 2020 Apr 7. doi:10.1002/uog.22045. [Epub ahead of print] PubMed PMID: 32266753.

3. Royal College of Obstetricians and Gynaecologists, Royal College of Midwives, Royal College of Paediatrics and Child Health, Public Health England and Health Protection Scotland. Coronavirus (COVID-19) Infection in Pregnancy. Information for healthcare professionals. Version 9: Published Wednesday 13 May 2020 [cited 2020 May 13]. Available from: https://www.rcog.org.uk/globalassets/documents/guidelines/2020-05-13-coronavirus-covid-19infection-in-pregnancy.pdf

4. Knight M, Bunch K, Vousden N, Morris E, Simpson N, Gale C, O'Brien P, Quigley M, Blocklehurst $\mathrm{P}$, Kurinczuk LL Characteristics and outcomes of pregnant women hospitalised with confirmed SARSCoV-2 infection in the UK: a national cohort study using the UK Obstetric Surveillance System (UKOSS) The UK Obstetric Surveillance System SARS-CoV-2 Infection in Pregnancy Collaborative Group. [cited 2020 May 13] Available from:https://www.npeu.ox.ac.uk/downloads/files/ukoss/annualreports/UKOSS\%20COVID-19\%20Paper\%20pre-print\%20draft\%2011-05-20.pdf

5. Arabi S, Vaseghi G, Heidari Z, et al. Clinical characteristics of COVID-19 infection in pregnant women: a systematic review and meta-analysis. MedRxiv preprint doi: [cited 2020 Apr 16]. Available from:https://doi.org/10.1101/2020.04.05.20053983.

6. Schwartz DA, Graham AL. Potential Maternal and Infant Outcomes from (Wuhan) Coronavirus 2019nCoV Infecting Pregnant Women: Lessons from SARS, MERS, and Other Human Coronavirus Infections. Viruses. 2020 Feb 10;12(2). pii: E194. doi: 10.3390/v12020194. PubMed PMID: 32050635.

7. Siston AM, Rasmussen SA, Honein MA, et al. Pandemic 2009 influenza A(H1N1) virus illness among pregnant women in the United States. JAMA 2010;303(15):1517-25. doi: 303/15/1517 [pii] 10.1001/jama.2010.479 [published Online First: 2010/04/22]

8. Donati S. [ItOSS Obstetric Surveillance] 26 March 2020. [cited 16 Apr 2020]. Available from:https://www.epicentro.iss.it/itoss/Italian (accessed 16 Apr 2020).

9. Donati S, Maraschini A, Lega I, et al.; Regional Maternal Mortality Working Group. Maternal mortality in Italy: Results and perspectives of record-linkage analysis. Acta Obstet Gynecol Scand. 2018 
Nov;97(11):1317-1324

10. The COVID-19 Task force of the Department of Infectious Diseases and the IT Service Istituto Superiore di Sanita. [Epidemics COVID-19, National update 28th Apr 2020]. Italian. [cited 2020 May 5]. Available from: https://www.epicentro.iss.it/coronavirus/bollettino/Bollettino-sorveglianza-integrataCOVID-19_28-aprile-2020.pdf.

11. Yan J, Guo J, Fan C, Juan J, Yu X, Li J, Feng L, Li C, Chen H, et al. Coronavirus disease 2019 (COVID-19) in pregnant women: A report based on 116 cases. Am J Obstet Gynecol. 2020 Apr 23. pii: S0002-9378(20)30462-2. doi: 10.1016/j.ajog.2020.04.014. [Epub ahead of print] PubMed PMID: 32335053; PubMed Central PMCID: PMC7177142

12. ISTAT National Institute of Statistics. [Education and training]. Italian. [cited 2020 May 5]. Available from:http://dati.istat.it/

13. Masocco M. [PASSI Surveillance. Italian data on overweight and obesity] [cited 2020 May 13] Available from: https://www.epicentro.iss.it/passi/dati/sovrappeso Italian

14. Campi R, Cartabia M, Miglio D, Bonati M Certificato di Assistenza al Parto (CedAP) Regione Lombardia. Analisi dell'evento nascita anno 2017 - Laboratorio per la Salute Materno Infantile, Dipartimento di Salute Pubblica, IRCCS-Istituto di Ricerche Farmacologiche Mario Negri Milano: Lombardia Region 2019. Italian. [cited 5 May 2020]. Available from:https://www.dati.lombardia.it/dataset/RapportoCedap/v7/4r-mqr5.

15. Perrone E, Formisano D, Gargano G et al. [Birth in Emilia-Romagna. 2018] Bologna: Emilia-Romagna Region, 2019. Italian. [cited 2020 May 5]. Available from: $h t t p: / /$ ww. saperidoc. $i t / f l e x / \mathrm{cm} /$ pages/ServeBLOB. php/L/IT/IDPagina/349

16. ECDC. Coronavirus disease 2019 (COVID-19) in the EU/EEA and the UK - eighth update 8 Apr 2020. [cited 2020 May 5]. Available from: https: //www. ecdc. europa. eu/sites/default/files/ documents/covid-19-rapid-risk-assessment-coronavirus-disease-2019-eighth-update-8april-2020. pdf.

17. Dashraath P, Jeslyn WJL, Karen LMX et al. Coronavirus Disease 2019 (COVID-19) Pandemic and Pregnancy. Am J Obstet Gynecol. 2020 Mar 23. pii:S0002-9378(20)30343-4. doi: 10.1016/j.ajog.2020.03.021. [Epub ahead of print] PubMed PMID: 32217113.

18. Zhang W, Zhao Y, Zhang F. The use of anti-inflammatory drugs in the treatment of people with severe coronavirus disease 2019 (COVID-19): The Perspectives of clinical immunologists from China; Clin Immunol. 2020 Mar 25;214:108393. doi: 10.1016/j.clim.2020.10839 [Epub ahead of print] PubMed PMID: 32222466.

19. Liu D, Li L, Wu X, Zheng D, et al. Pregnancy and perinatal outcomes of women with coronavirus disease (COVID-19) pneumonia: a preliminary analysis. AJR Am J Roentgenol. 2020 Mar 18:1-6. doi: 10.2214/AJR.20.23072. [Epub ahead of print] PubMed PMID: 32186894.

20. Moro F, Buonsenso D, Moruzzi MC, Inchingolo R, Smargiassi A, Demi L, Larici AR, Scambia G, Lanzone A, Testa AC. How to perform lung ultrasound in pregnant women with suspected COVID-19 infection. Ultrasound Obstet Gynecol. 2020 Mar 24. doi: 10.1002/uog.22028. [Epub ahead of print] PubMed PMID: 32207208

21. Bardon VF, Salomon LJ, Leruez-Ville M, Ville Y. How should we treat pregnant women infected with SARS-CoV-2? BJOG. 2020 Apr 23. doi: 10.1111/1471-0528.16270. [Epub ahead of print] PubMed PMID: 32324956

22. Maged MC, Landon MB, Saade GR Protection by Exclusion Another Missed Opportunity to Include Pregnant Women in Research During the Coronavirus Disease 2019 (COVID-19) Pandemic. Obstet Gynecol 2020;00:1-3 DOI:10.1097/AOG.0000000000003924

23. Donati S, Maraschini A, Dell'Oro S, Lega I, D'Aloja P and the Regional Maternal Mortality Working Group. The way to move beyond the numbers: the lesson learnt from the Italian Obstetric Surveillance SystemAnn Ist Super Sanita 2019;55(4): 363-370.

24. Maraschini A, Lega I, D'Aloja P, Buoncristiano M, Dell'Oro S, Donati S;Regional Obstetric Surveillance System Working Group. Women undergoing peripartum hysterectomy due to obstetric hemorrhage: A prospective population-based study. Acta Obstet Gynecol Scand. 2019 Sep 13. doi: 
10.1111/aogs.13727.

Figure and Tables

Figure 1. Number of COVID-19 cases notified by Region, from February 25 to April 22, 2020

Table 1. Women's socio-demographic and obstetric characteristics by occurrence of COVID-19 pneumonia

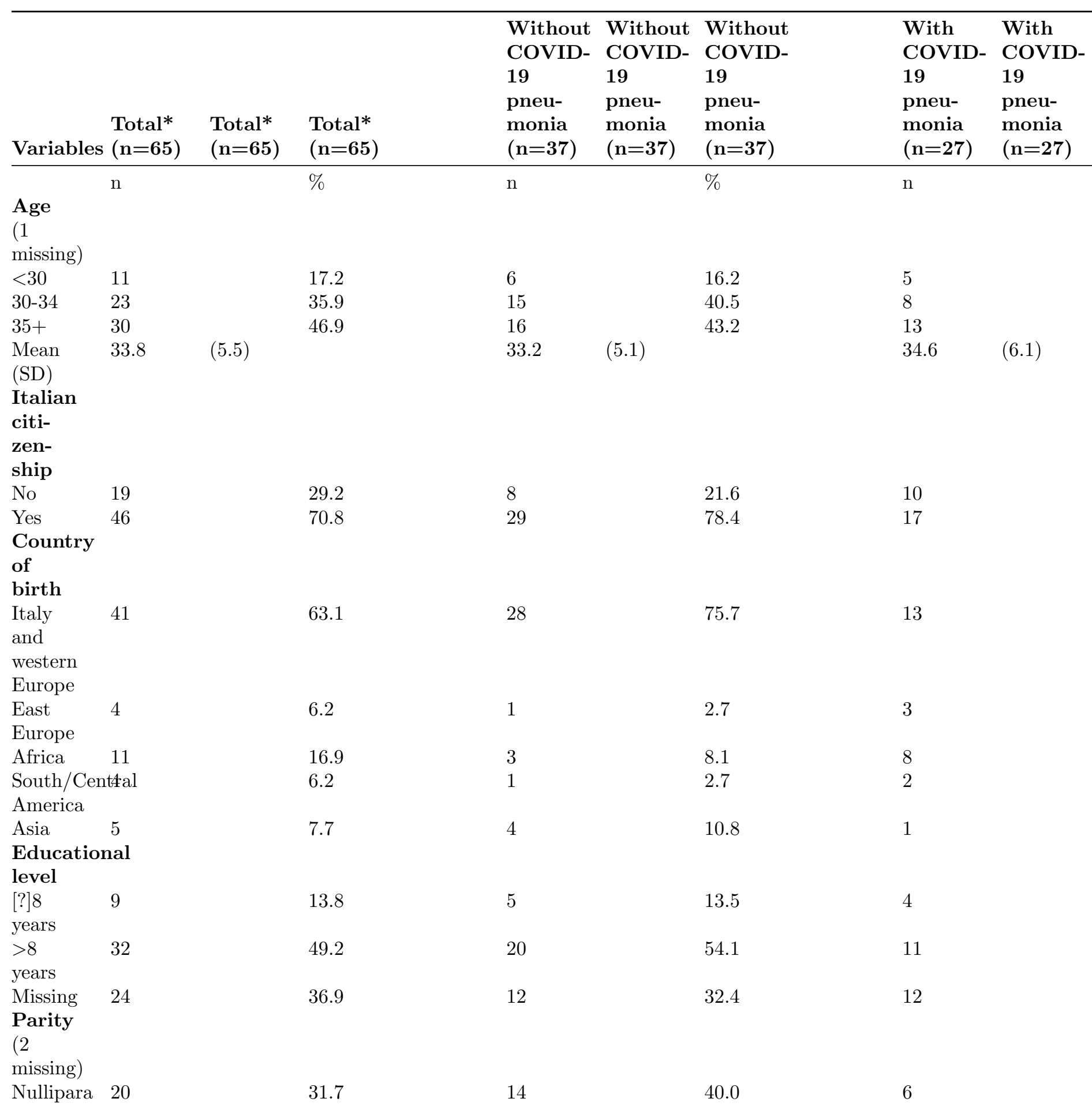




\begin{tabular}{|c|c|c|c|c|c|c|c|c|}
\hline Variables & $\begin{array}{l}\text { Total* } \\
(n=65)\end{array}$ & $\begin{array}{l}\text { Total* } \\
(\mathrm{n}=65)\end{array}$ & $\begin{array}{l}\text { Total* } \\
(\mathrm{n}=65)\end{array}$ & $\begin{array}{l}\text { Without } \\
\text { COVID- } \\
19 \\
\text { pneu- } \\
\text { monia } \\
(\mathrm{n}=37)\end{array}$ & $\begin{array}{l}\text { Without } \\
\text { COVID- } \\
19 \\
\text { pneu- } \\
\text { monia } \\
(\mathrm{n}=37)\end{array}$ & $\begin{array}{l}\text { Without } \\
\text { COVID- } \\
19 \\
\text { pneu- } \\
\text { monia } \\
(\mathrm{n}=37)\end{array}$ & $\begin{array}{l}\text { With } \\
\text { COVID- } \\
19 \\
\text { pneu- } \\
\text { monia } \\
(\mathbf{n}=27)\end{array}$ & $\begin{array}{l}\text { With } \\
\text { COVID- } \\
19 \\
\text { pneu- } \\
\text { monia } \\
(n=27)\end{array}$ \\
\hline $\begin{array}{l}\text { Multipara } \\
\text { Previous } \\
\text { co- } \\
\text { mor- } \\
\text { bidi- } \\
\text { ties }\end{array}$ & 43 & & 68.3 & 21 & & 60.0 & 21 & \\
\hline No & 46 & & 70.8 & 32 & & 86.5 & 13 & \\
\hline Yes & 19 & & 29.2 & 5 & & 13.5 & 14 & \\
\hline Obesity & 11 & & 16.9 & 3 & & 8.1 & 8 & \\
\hline $\begin{array}{l}\text { Autoimmu } \\
\text { disease }\end{array}$ & & & 6.2 & 1 & & 2.7 & 3 & \\
\hline Diabetes & 2 & & 3.1 & 0 & & 0.0 & 2 & \\
\hline $\begin{array}{l}\text { Hypertensi } \\
\text { Other }\end{array}$ & ion & & $\begin{array}{l}3.1 \\
3.1\end{array}$ & $\begin{array}{l}0 \\
1\end{array}$ & & $\begin{array}{l}0.0 \\
2.7\end{array}$ & $\begin{array}{l}2 \\
1\end{array}$ & \\
\hline $\begin{array}{l}\text { Smoking } \\
\text { in } \\
\text { preg- } \\
\text { nancy }\end{array}$ & & & & & & & & \\
\hline Never & 50 & & 76.9 & 27 & & 73.0 & 22 & \\
\hline $\begin{array}{l}\text { Quit } \\
\text { before } \\
\text { pregnancy }\end{array}$ & 6 & & 9.2 & 4 & & 10.8 & 2 & \\
\hline $\begin{array}{l}\text { Quit } \\
\text { during } \\
\text { pregnancy }\end{array}$ & 2 & & 3.1 & 2 & & 5.4 & 0 & \\
\hline $\begin{array}{l}\text { Smoked } \\
\text { during } \\
\text { pregnancy }\end{array}$ & 0 & & 0.0 & 0 & & 0.0 & 0 & \\
\hline $\begin{array}{l}\text { Missing } \\
\text { Gestation } \\
\text { age } \\
\text { at } \\
\text { diag- } \\
\text { nosis } \\
(1 \\
\text { missing) }\end{array}$ & $\begin{array}{c}7 \\
\text { nal }\end{array}$ & & 10.8 & 4 & & 10.8 & 3 & \\
\hline $\begin{array}{l}{[?] 14} \\
\text { weeks }\end{array}$ & 10 & & 15.6 & 6 & & 16.7 & 3 & \\
\hline $\begin{array}{l}15-27 \\
\text { weeks }\end{array}$ & 33 & & 51.6 & 16 & & 44.4 & 17 & \\
\hline $\begin{array}{l}{[?] 28} \\
\text { weeks } \\
\text { Multiple } \\
\text { preg- } \\
\text { nancy }\end{array}$ & 21 & & 32.8 & 14 & & 38.9 & 7 & \\
\hline
\end{tabular}




\begin{tabular}{|c|c|c|c|c|c|c|c|c|}
\hline Variables & $\begin{array}{l}\text { Total }^{*} \\
(\mathrm{n}=65)\end{array}$ & $\begin{array}{l}\text { Total }^{*} \\
(\mathrm{n}=65)\end{array}$ & $\begin{array}{l}\text { Total }^{*} \\
(\mathrm{n}=65)\end{array}$ & $\begin{array}{l}\text { Without } \\
\text { COVID- } \\
19 \\
\text { pneu- } \\
\text { monia } \\
(n=37)\end{array}$ & $\begin{array}{l}\text { Without } \\
\text { COVID- } \\
19 \\
\text { pneu- } \\
\text { monia } \\
(\mathrm{n}=37)\end{array}$ & $\begin{array}{l}\text { Without } \\
\text { COVID- } \\
19 \\
\text { pneu- } \\
\text { monia } \\
(n=37)\end{array}$ & $\begin{array}{l}\text { With } \\
\text { COVID- } \\
19 \\
\text { pneu- } \\
\text { monia } \\
(\mathrm{n}=27)\end{array}$ & $\begin{array}{l}\text { With } \\
\text { COVID- } \\
19 \\
\text { pneu- } \\
\text { monia } \\
(n=27)\end{array}$ \\
\hline $\mathrm{No}$ & 62 & & 95.4 & 34 & & 91.9 & 27 & \\
\hline Yes & 3 & & 4.6 & 3 & & 8.1 & 0 & \\
\hline $\begin{array}{l}\text { Flu } \\
\text { vac- } \\
\text { cine }\end{array}$ & & & & & & & & \\
\hline No & 61 & & 93.8 & 35 & & 94.6 & 25 & \\
\hline Yes & 4 & & 6.2 & 2 & & 5.4 & 2 & \\
\hline
\end{tabular}

* One case of Chlamydia pneumonia has been excluded from the stratified analysis

Table 2. Women's symptoms and outcomes by occurrence of COVID-19 pneumonia

Variables

Total*

$(\mathrm{n}=65)$

Total*

$(\mathrm{n}=65)$

Without COVID-19 pneumonia

$(\mathrm{n}=37)$

Without COVID-19 pneumonia

$(\mathrm{n}=37)$

With COVID-19 pneumonia

$(\mathrm{n}=27)$

With COVID-19 pneumonia

$(\mathrm{n}=27)$

$\mathbf{n}$

$\%$

n

$\%$

n

$\%$

Symptoms

Cough

46 
70.8

21

56.8

24

88.9

Fever

41

63.1

17

45.9

23

85.2

General weakness

31

47.7

14

37.8

16

59.3

Dyspnoea

25

38.5

7

18.9

18

66.7

Muscle/joint pain

17

26.2

8

21.6

9

33.3

Sore throat 
22.2

\section{Headache}

14

21.5

9

24.3

5

18.5

Rhinorrhea

13

20.0

7

18.9

6

22.2

Vomiting/Diarrhea

9

13.8

5

13.5

4

14.8

Chest pain

8

12.3

4

10.8

4

14.8 


\section{Cojunctivitis}

1

1.5

0

0.0

1

3.7

No symptoms

7

10.8

7

18.9

0

0.0

\section{Outcomes}

Severe morbidity

3

4.6

0

0.0

3

11.1

ARDS

2

3.1

0

0.0

2

7.4

Renal failure

1

1.5

0

0.0 
Death

0

0.0

0

0.0

0

0.0

* One case of Chlamydia pneumonia has been excluded from the stratified analysis

Table 3. Diagnosis and therapy by COVID-19 pneumonia among hospitalised women

Variables

Total*

$(\mathrm{n}=43)$

Total*

$(\mathrm{n}=43)$

Without COVID-19 pneumonia

$(\mathrm{n}=15)$

Without COVID-19 pneumonia

$(\mathrm{n}=15)$

With COVID-19 pneumonia

$(\mathrm{n}=27)$

With COVID-19 pneumonia

$(\mathrm{n}=27)$

$\mathbf{n}$

$\%$

n

$\%$

$\mathbf{n}$

$\%$

\section{Diagnosis}

Imaging techniques:

No exams

7 


\section{3 \\ 7 \\ 46.7 \\ 0 \\ 0.0}

Chest X-ray

20

46.5

5

33.3

14

51.9

Chest TC

3

7.0

0

0.0

3

11.1

Lung ultrasound

4

9.3

0

0.0

4

14.8

Chest X-ray + Lung ultrasound

8

18.6

2

13.3

6

22.2

Chest X-ray + Chest TC 
6.7

0

0.0

Vital signs and laboratory reports

Body temperature $>37.5{ }^{\circ} \mathrm{C}$

15

34.9

4

26.7

11

40.7

Lymphopenia (<1500 mm3)

22

51.2

5

33.3

17

63.0

$\mathrm{CRP}$ values $>10 \mathrm{mg} / 100 \mathrm{ml}$

13

30.2

1

6.7

12

44.4

Oxygen saturation $<95 \%$

8

18.6

1

6.7

7 
25.9

Blood gas test

Not performed

13

30.2

8

53.3

4

14.8

Performed, normal result

14

32.6

6

40.0

8

29.6

Performed, pathological result

16

37.2

1

6.7

15

55.6

Drug therapy

Antiviral drugs:

22

51.2

4

26.7

17

63.0

Lopinavir

15

34.9 
40.7

Darunavir

6

14.0

1

6.7

5

18.5

Norvir, Tolicizumab, Remdesivir

3

7.0

0

0.0

3

11.1

Hydroxicloroquine

22

51.2

3

20.0

18

66.7

Empirical antibiotic therapy

20

46.5

4

26.7

16

59.3

Targeted antibiotic therapy

4 
13.3

2

7.4

Antenatal coricosteroids for fetal lung maturation

5

11.6

2

13.3

3

11.1

\section{Critical care}

Non invasive respiratory support

19

44.2

2

13.3

17

63.0

Invasive respiratory support

8

18.6

0

0.0

8

29.6

Orotracheal intubation

1

2.3

0

0.0

1

3.7 
Admission to sub-intensive care unit

1

2.3

0

0.0

1

3.7

Admission to intensive care unit

3

7.0

0

0.0

3

11.1

Extracorporeal membrane oxygenation

0

0.0

0

0.0

0

0.0

* One case of Chlamydia pneumonia has been excluded from the stratified analysis

\section{Hosted file}

Figure 1.docx available at https://authorea.com/users/323054/articles/451971-coronavirus-andpregnancy-in-italy-results-of-the-national-population-based-cohort-study-coordinated-bythe-italian-obstetric-surveillance-system 